\author{
Original Contribution
}

\title{
Ceruloplasmin expression by human peripheral blood lymphocytes: A new link between immunity and iron metabolism
}

\author{
João Banha ${ }^{\mathrm{a}, 1}$, Liliana Marques ${ }^{\mathrm{a}, 1}$, Rita Oliveira ${ }^{\mathrm{a}}$, Maria de Fátima Martins ${ }^{\mathrm{a}}$, Eleonora Paixão ${ }^{\text {a }}$, \\ Dina Pereira $^{b}$, Rui Malhó ${ }^{c}$, Deborah Penque ${ }^{a}$, Luciana Costa ${ }^{a, *}$ \\ a Instituto Nacional de Saúde Dr. Ricardo Jorge, I.P. (INSA), Lisboa, Portugal \\ ${ }^{\mathrm{b}}$ Hospital de Reynaldo dos Santos, Vila Franca De Xira, Portugal \\ c Faculdade de Ciências, ICAT, Universidade de Lisboa, Portugal
}

Received 27 July 2007; revised 24 September 2007; accepted 11 October 2007

Available online 22 October 2007

\begin{abstract}
Ceruloplasmin (CP) is a multicopper oxidase involved in the acute phase reaction to stress. Although the physiological role of CP is uncertain, its role in iron $(\mathrm{Fe})$ homeostasis and protection against free radical-initiated cell injury has been widely documented. Previous studies showed the existence of two molecular isoforms of CP: secreted CP (sCP) and a membrane glycosylphosphatidylinositol (GPI)-anchored form of CP (GPI$\mathrm{CP}$ ). SCP is produced mainly by the liver and is abundant in human serum whereas GPI-CP is expressed in mammalian astrocytes, rat leptomeningeal cells, and Sertolli cells. Herein, we show using RT-PCR that human peripheral blood lymphocytes (huPBL) constitutively express the transcripts for both CP molecular isoforms previously reported. Also, expression of CP in huPBL is demonstrated by immunofluorescence with confocal microscopy and flow cytometry analysis using cells isolated from healthy blood donors with normal Fe status. Importantly, the results obtained show that natural killer cells have a significantly higher CP expression compared to all other major lymphocyte subsets. In this context, the involvement of lymphocyte-derived CP on host defense processes via its anti/prooxidant properties is proposed, giving further support for a close functional interaction between the immune system and the Fe metabolism.
\end{abstract}

(C) 2007 Elsevier Inc. All rights reserved.

Keywords: Ceruloplasmin; Peripheral blood lymphocytes; Iron; Copper; NK cells

\section{Introduction}

The molecular link between iron $(\mathrm{Fe})$ and copper $(\mathrm{Cu})$ metabolism has been identified as the serum multicopper protein

Abbreviations: $\mathrm{CP}$, ceruloplasmin; CTL, cytotoxic T lymphocyte; $\mathrm{Cu}$ copper; Fe, iron; Ft, ferritin; GPI-CP, membrane glycosylphosphatidylinositolanchored ceruloplasmin; HBSS, Hank's balanced salt solution; HH, hereditary hemochromatosis; huPBL, human peripheral blood lymphocytes; huPBMn, human peripheral blood monocytes; LDLR, low-density lipoprotein receptor; $\mathrm{mAb}$, monoclonal antibody; MHC, major histocompatibility complex; NK cell, natural killer cell; NKT cell, natural killer T cell; PBMC, peripheral blood mononuclear cells; RT-PCR, reverse transcription-polymerase chain reaction; sCP, secreted ceruloplasmin; Tf, transferrin; Th, T helper (cell).

* Corresponding author. Centro de Biopatologia, Instituto Nacional de Saúde Dr. Ricardo Jorge, I.P., Av. Padre Cruz, 1649-016 Lisboa, Portugal. Fax: +351 217526470 .

E-mail address: 1costa@insa.min-saude.pt (L. Costa).

${ }^{1}$ J.B. and L.M. equally contributed to this work. ceruloplasmin (CP) [1]. CP is an abundant $\alpha_{2}$-glycoprotein containing over $95 \%$ of the $\mathrm{Cu}$ found in the plasma of all vertebrate species [2]. The protein is synthesized mainly in the liver as a single polypeptide chain of 1046 amino acids and secreted into the plasma with six to seven atoms of $\mathrm{Cu}$ bound per molecule. CP has been implicated in Fe metabolism mostly because of its catalytic oxidation of Fe(II) to Fe(III) (ferroxidase activity) [3] with its subsequent incorporation into apotransferrin [4] or into the $\mathrm{Fe}$ storage protein ferritin $(\mathrm{Ft})$ [5]. Nevertheless, the physiological role of CP is not well defined but may include extracellular antioxidant activity by promoting $\mathrm{Fe}$ mobilization and thus preventing metal-catalyzed free radical tissue damage [6,7]. Alternatively, several studies suggest that $\mathrm{CP}$ may also exhibit potent prooxidant activity [8]. Despite the unknown function of such $\mathrm{CP}$ prooxidative activity, it is likely that the protein is involved in host defense and repair processes mediated by the immune system, namely 
during inflammation [9] and hyperoxia [10]. In fact, $\mathrm{CP}$ is an acute-phase reactant with its serum concentration increasing during pregnancy, infection, tissue injury, and certain malignant disorders [11]. Supporting the possible role of CP in host protective function, early studies have shown that respiratory burst and microbicidal activity of phagocytic cells are suppressed by $\mathrm{Cu}$ deficiency $[12,13]$ while changes in splenic lymphoid cell subsets have been observed in $\mathrm{Cu}$-deficient rats [14]. In addition, several cytokines and other factors are known to induce CP synthesis by hepatic cells including interferongamma [15], interleukin-1, interleukin-6 [16], tumor necrosis factor alpha, and lipopolysaccharide [17],suggesting a link between this protein and immune function.

On the other hand, the link between Fe metabolism and cellmediated immunity is now well established [18]. The postulate that the immune system could have a role in monitoring tissue $\mathrm{Fe}$ toxicity as part of its surveillance function was reported over 25 years ago [19]. Immunological anomalies observed in patients with hereditary hemochromatosis $(\mathrm{HH})$ [20-22] and animal models of Fe overload [23] strongly supported this original concept. Also, the discovery of the HFE gene associated with $\mathrm{HH}$ as a new major histocompatibility complex (MHC) class I gene [24] provided conclusive evidence for the role of the immune system regulating Fe homeostasis. However, a direct relationship among human peripheral blood lymphocytes (huPBL), CP, and Fe metabolism has never been investigated.

Although CP is generally considered a serum protein secreted by the liver, extrahepatic expression has also been observed [25-27]. In particular, a membrane-bound glycosylphosphatidylinositol (GPI)-anchored form of CP (GPI-CP) localized at the surface of mammalian astrocytes [28], rat leptomeningeal cells [29], and Sertoli cells [30] was reported. However, despite the detection of CP mRNA in immune cells [31,32], the characterization of the specific molecular isoform (s) expressed by huPBL has never been attempted.

In this study, reverse transcription-PCR (RT-PCR) was used to examine whether huPBL constitutively express $\mathrm{CP}$ and to identify its specific transcripts. Also, the expression of the mature $\mathrm{CP}$ protein in the major lymphocyte subpopulations isolated from peripheral blood collected from healthy volunteers with normal iron status was investigated by flow cytometry while protein localization was studied by confocal microscopy analysis of immunofluorescence staining. The results obtained showed that huPBL express both secreted CP (sCP) and GPI-CP transcripts. Also, we showed that $\mathrm{CP}$ protein is localized at the huPBL surface. Furthermore, we demonstrated that CP expression at the huPBL surface is highly specific to the natural killer (NK) cell lymphocyte subset, suggesting an important role for huPBL-associated CP in the relationship among innate immunity, Fe metabolism, and oxidative stress.

\section{Materials and methods}

\section{Individuals}

Twenty-four healthy volunteers from both genders (11 women and $13 \mathrm{men})$ aged 20 to 60 years $(40.9 \pm 2.22$ years, mean age $\pm \mathrm{SD}$ ) were included in this study (INSA, Lisbon). After informed consent, peripheral blood samples were obtained by venous puncture to determine hematological and biochemical parameters of $\mathrm{Fe}$ metabolism. Exclusion criteria included any Fe loading or deficiency controlled by measurement of hematological and biochemical Fe metabolism markers. The study was approved by the INSA-Ethical Committee.

\section{Hematological and biochemical markers of Fe metabolism}

Cell blood counts were performed in EDTA-collected peripheral blood from healthy human volunteers using an automated hematology counter Coulter MAXM and included determination of hemoglobin $(\mathrm{Hb})$, red blood cell (RBC) count, mean cell volume $(\mathrm{MCV})$, mean cell $\mathrm{Hb}(\mathrm{MCH})$, mean cell $\mathrm{Hb}$ concentration (MCHC), white blood cell (WBC) count, and differential WBC count.

Serum Fe, transferrin (Tf), and total Fe binding capacity (TIBC) were measured using an automated analyzer BM/Hitachi 911 (Boehringer Mannheim, Roche) by an enzymatic colorimetric assay. Tf saturation was calculated from the TIBC and serum Fe values. Quantification of serum Ft was performed by an immunometric assay using an Immulite analyzer. Serum CP was measured by nephelometry using a Beckman Array System analyzer.

\section{Cell isolation and preparation for RNA extraction}

Human peripheral blood mononuclear cells (PBMC) were isolated from buffy coats by density gradient centrifugation using Lymphoprep (Axis-Shield, Norway) and washed with Hank's balanced salt solution (HBSS) (GIBCO BRL, Invitrogen). RBC were lysed in lysis solution (10 mM Tris, $16 \mathrm{mM}$ $\mathrm{NH}_{4} \mathrm{Cl}, \mathrm{pH}$ 7.4) for $10 \mathrm{~min}$ at $37^{\circ} \mathrm{C}$. The remaining PBMC were washed in HBSS and resuspended in RPMI 1640 culture medium supplemented with GlutaMAX I, 25 mM Hepes buffer (GIBCO BRL, Invitrogen), and $10 \%$ fetal bovine serum (GIBCO BRL, Invitrogen). For lymphocyte enrichment, each PBMC suspension was seeded in T75 culture flasks followed by a 2-h incubation at $37{ }^{\circ} \mathrm{C}$ in an atmosphere of $5 \% \mathrm{CO}_{2}$. Cells in suspension were collected and washed in HBSS. For monocyteenriched PBMC, the remaining adherent cells in the culture flasks were washed with HBSS several times until no cells were observed in suspension. Cells were then collected and washed in HBSS.

HepG2 cells cultured in William's E medium (GIBCO BRL, Invitrogen) supplemented with $10 \%$ fetal bovine serum and $1 \%$ penicillin-streptomycin (GIBCO BRL, Invitrogen) were collected from a confluent T25 culture flask and washed in Dulbecco's PBS (GIBCO BRL, Invitrogen).

\section{$R N A$ extraction and RT-PCR}

Human lymphocyte-enriched PBMC, monocyte-enriched PBMC, and HepG2 cells were lysed in RLT buffer (QIAGEN) with $1 \% \beta$-mercaptoethanol, homogenized by passing the lysates through a $20 \mathrm{G}$ needle for at least 10 times followed by 
centrifugation in a QIAshredder spin column (QIAGEN). The homogenized lysates were stored at $-80^{\circ} \mathrm{C}$ until RNA extraction. Total RNA was extracted according to RNeasy Protect Mini Kit protocol (QIAGEN), followed by quantitative and qualitative analysis. cDNA was synthesized with oligo(dT) primers according to the Superscript First-Strand cDNA Synthesis System procedure (Invitrogen). The resulting cDNA strand was then used as template for PCR with primers specifically designed for lowdensity lipoprotein receptor (LDLR) [33], CD81 (lymphocytespecific marker), CD33 (monocyte and macrophage-specific marker), sCP, and GPI-CP. Primers were designed for the $3^{\prime}$ terminal sequence of $\mathrm{CP}$ transcripts in order to distinguish between sCP and GPI-CP mRNA, with the reverse primers being designed for exons 19 and 20, respectively. The sequences of all primers are shown in Table 2 (view Supplementary data). The PCR protocol was as follows: each reaction contained $0.2 \mathrm{mM}$ of each deoxynucleotide triphosphate (dNTP) (Bioline, UK), $1.5 \mathrm{mM}$ $\mathrm{MgCl}_{2}$ (Bioline, UK) for LDLR, CD81, and CD33 PCR and $3.0 \mathrm{mM} \mathrm{MgCl}_{2}$ for sCP and GPI-CP PCR conditions, $10 \mathrm{pmol}$ of each primer (Invitrogen), 1.0 units of Biotaq polymerase (Bioline, UK), 10X ammonium buffer (Bioline, UK), 1-3 $\mu$ l of each cDNA sample (100-200 ng/ $\mu \mathrm{l})$, and water up to a final volume of $25 \mu \mathrm{l}$. For CD33 and GPI-CP PCR, 10\% dimethyl sulfoxide was also used. The PCR conditions are shown in Table 3 (view Supplementary data). After final extension, all RT-PCR products were cooled down and stored at $4{ }^{\circ} \mathrm{C}$ until posterior analysis.

RT-PCR products were separated in a $1.5 \%$ agarose gel (GIBCO BRL Life Technologies, Invitrogen) stained with ethidium bromide (Sigma-Aldrich) and analyzed using Quantity One 4.3.0 software (Bio-Rad Laboratories). Amplified fragments were purified using EXOSAP (GE Healthcare, Sweden), followed by DNA sequencing. The resulting sequences were analyzed using BioEdit 7.0.5.3 software [34] for confirmation of RT-PCR products identity.

\section{Immunophenotyping and flow cytometry analysis}

Fresh peripheral blood cells were obtained from $1 \mathrm{ml}$ of EDTA-collected peripheral blood. RBC were lysed in lysis solution for $10 \mathrm{~min}$ at $37^{\circ} \mathrm{C}$ and the remaining white blood cells were then washed in PBS supplemented with $0.2 \%$ BSA (SigmaAldrich), resuspended, and plated in 96-well round-bottomed microtiter plates (Nunclon, Denmark) at $3 \times 10^{5}$ cells $/$ well.

Cells were stained for $\mathrm{CP}$ using the rabbit anti-human CP (DakoCytomation, Denmark) as primary antibody (Ab) followed by incubation with a swine $\mathrm{F}\left(\mathrm{ab}^{\prime}\right)_{2}$ anti-rabbit FITCconjugated as secondary Ab (DakoCytomation, Denmark). To determine CP mean fluorescence intensity (MFI) in specific lymphocyte subsets, monoclonal $\mathrm{Ab}(\mathrm{mAb}) \mathrm{CD} 4-\mathrm{PE}, \mathrm{CD} 8-\mathrm{PE}$, CD19-PE, or CD16/CD56-PE conjugated were used separately combined with $\mathrm{mAb}$ CD45-PerCP conjugated for lymphocyte gating and $\mathrm{mAb} \mathrm{CD} 3-\mathrm{APC}$ conjugated for positive or negative selection of $\mathrm{T}$ cells. HuPBL subpopulations within the "lymphogate" were designated according to the expression of its surface markers: $\mathrm{T}$ helper lymphocyte $(\mathrm{Th})(\mathrm{CD} 3+\mathrm{CD} 4+)$, cytotoxic T lymphocyte (CTL) (CD3+CD8+), B lymphocytes (CD3-CD19+), NK (CD3-CD16+/CD56+), and natural killer T
(NKT) cells $(\mathrm{CD} 3+\mathrm{CD} 16+/ \mathrm{CD} 56+)$. Absence of unspecific binding of anti-rabbit FITC-conjugated secondary Ab was verified by cell staining in the absence of primary Ab. Also, unstained cells were used as negative control, to determine autofluorescence. All mAb were purchased from Pharmingen.

After staining, cells were washed twice in PBS/BSA solution and resuspended in FACS Flow solution followed by flow cytometry analysis using a FACSCalibur (Becton Dickinson). Analysis of data was performed using the CellQuest Software. Results are presented in Arbitrary Units (AU) resulting from the ratio between the MFI of stained cells and the MFI of nonstained cells in the same population.

\section{Immunofluorescence staining for confocal microscopy analysis}

Lymphocyte-enriched human PBMC samples were prepared as described previously. Cells were washed, fixed in $4 \%$ formaldehyde in PBS at $4{ }^{\circ} \mathrm{C}$ for $30 \mathrm{~min}$, washed, and preserved in PBS at $4{ }^{\circ} \mathrm{C}$. Cells were adhered onto silane-coated slides (Sigma-Aldrich) using Shandon cytospin III (GPI, Inc., USA) and blocked with $1 \%$ BSA in PBS for 45 min at room temperature, followed by a 45-min incubation with 1:50 sheep antihuman CP IgG-FITC conjugated (BIOTREND GmbH, Germany) diluted in blocking solution at room temperature. Cells were washed three times with $0.5 \%$ BSA in PBS for 5 min at room temperature. Dyes were mounted in Vectashield conjugated with DAPI (Vector laboratories, Ltd., UK) and observed by confocal microscopy.

\section{Confocal microscopy analysis}

Dyes were imaged using a Bio-Rad MCR-600 (Microscience Ltd, Hemel Hempstead, UK) confocal laser scanning microscope

Table 1

Hematological and biochemical markers of Fe metabolism measured in peripheral blood obtained from human healthy volunteers $(n=24$, mean $\pm \mathrm{SE})$

\begin{tabular}{lcccl}
\hline & Total $(n=24)$ & Men $(n=11)$ & Women $(n=13)$ & $\mathbf{P}^{\mathbf{b}}$ \\
\hline Hb $(\mathrm{g} / \mathrm{dl})$ & $14,3 \pm 0,2^{\mathbf{a}}$ & $15,3 \pm 0,2$ & $13,6 \pm 0,3$ & 0,013 \\
RBC $\left(\times 10^{12} / \mathrm{l}\right)$ & $4,7 \pm 0,8$ & $4,9 \pm 0,1$ & $4,5 \pm 0,1$ & 0,034 \\
MCV $(\mathrm{fl})$ & $87,3 \pm 0,9$ & $86,0 \pm 1,3$ & $89,0 \pm 1,9$ & n.s. \\
MCH $(\mathrm{pg})$ & $30,6 \pm 0,3$ & $30,9 \pm 0,5$ & $30,2 \pm 0,8$ & n.s. \\
MCHC $(\mathrm{g} / \mathrm{dl})$ & $35,1 \pm 0,3$ & $33,3 \pm 0,53$ & $34,08 \pm 0,56$ & 0,000 \\
WBC $\left(\times 10^{6} / \mathrm{ml}\right)$ & $6,3 \pm 0,4$ & $6,1 \pm 0,5$ & $6,6 \pm 0,9$ & n.s. \\
Neutrophils $\left(\times 10^{6} / \mathrm{ml}\right)$ & $3,6 \pm 0,2$ & $3,8 \pm 0,3$ & $3,5 \pm 0,3$ & n.s. \\
Monocytes $\left(\times 10^{6} / \mathrm{ml}\right)$ & $0,5 \pm 0,1$ & $0,5 \pm 0,1$ & $0,4 \pm 0,1$ & n.s. \\
Lymphocytes $\left(\times 10^{6} / \mathrm{ml}\right)$ & $2,0 \pm 0,2$ & $1,6 \pm 0,2$ & $2,4 \pm 0,6$ & n.s. \\
Fe $(\mu \mathrm{g} / \mathrm{dl})$ & $99,6 \pm 5,7$ & $85,8 \pm 11,5$ & $96,8 \pm 8,4$ & n.s. \\
Tf $(\mathrm{mg} / \mathrm{dl})$ & $252,5 \pm 8,3$ & $250,2 \pm 15,0$ & $262,0 \pm 15,1$ & n.s. \\
TIBC $(\mathrm{mg} / \mathrm{dl})$ & $315,6 \pm 10,4$ & $313,0 \pm 18,9$ & $327,5 \pm 18,8$ & n.s. \\
Tfsat $(\%)$ & $32,0 \pm 2,0$ & $27,8 \pm 4,2$ & $30,1 \pm 3,1$ & n.s. \\
Ft $(\mathrm{ng} / \mathrm{ml})$ & $84,2 \pm 16,3$ & $130,7 \pm 39,6$ & $39,8 \pm 12,0$ & 0,018 \\
$\mathrm{CP}(\mathrm{ng} / \mathrm{ml})$ & $30,2 \pm 1,5$ & $27,9 \pm 5,85$ & $35,3 \pm 6,66$ & 0,009 \\
\hline
\end{tabular}

n.s., not significant. Hemoglobin, $\mathrm{Hb}$; red blood cell count, RBC; mean cell volume, $\mathrm{MCV}$; mean cell hemoglobin, $\mathrm{MCH}$; mean cell hemoglobin concentration, MCHC; white blood cell count, WBC; serum iron, Fe; transferrin, Tf; total iron binding capacity, TIBC; Tf saturation, Tfsat; serum ferritin, Ft; serum ceruloplasmin, $\mathrm{CP}$.

${ }^{a}$ Arithmetic mean \pm 1 standard error.

${ }^{\mathrm{b}}$ Comparison between genders (men and women). 
(CLSM) coupled to an Olympus BX-51 scope. Images were collected in F1 scanning mode ( $\sim 1 \mathrm{~s}$ per frame), with a 3\% laser intensity, an electronic zoom of $\times 2$ or $\times 3$. A $\times 60$ Plan Apo dry objective (NA $=0.85)$ (Olympus) was used. The black level and gain settings were adjusted so that the average background pixel intensity was between 0 and 10 and the fluorescent signal coming from the cells was between 40 and 220. The degree of filter block cross talk was estimated and a simple method was devised to establish the confocal settings at which cross talk was minimal [35]. Once defined, the settings were kept constant throughout the data collection. Fluorescence analysis was performed with the software package Image-Pro Plus 4.0 (Media Cybernetics).

\section{Statistical analysis}

The association between CP expression in total huPBL and CP expressed in differential lymphocyte subpopulations (Th, CTL, B, NK, NKT cells) was measured by the Pearson and Spearman correlation coefficients. Confidence intervals for mean at $95 \%$ level were calculated.

In order to estimate the impact between $\mathrm{CP}$ expression in total huPBL and CP expressed in each lymphocyte subsets, a linear regression model was adjusted $(Y=\alpha+\beta x+\varepsilon$, where $Y$ is the dependent variable, $x$ is the independent variable, $\alpha$ is the constant, $\beta$ is the coefficient of independent variable, and $\varepsilon$ is the random error).

For model diagnosis we used the adjusted $R^{2}$, KolmogorovSmirnov test for the assumption "Normally" distributed residuals and the Durbin-Watson for the assumption of autocorrelation. Values of $P \leq 0.05$ were accepted as statistically significant. SPSS Base 14.0 software was used to perform all statistical analysis (SPSS inc. 2005).

\section{Results}

\section{Hematological and biochemical markers of Fe metabolism}

Results from the measurement of hematological and biochemical parameters are presented in Table 1. According to the data obtained, all participants in this study showed a normal $\mathrm{Fe}$ metabolism with no biochemical and hematological evidence of Fe overload or deficiency. Significant differences between genders were found in $\mathrm{Hb}$, total count of $\mathrm{RBC}, \mathrm{MCHC}$, $\mathrm{Ft}$, and $\mathrm{CP}$. In contrast, no association between age and hematological or biochemical markers of $\mathrm{Fe}$ metabolism was found in all individuals studied.
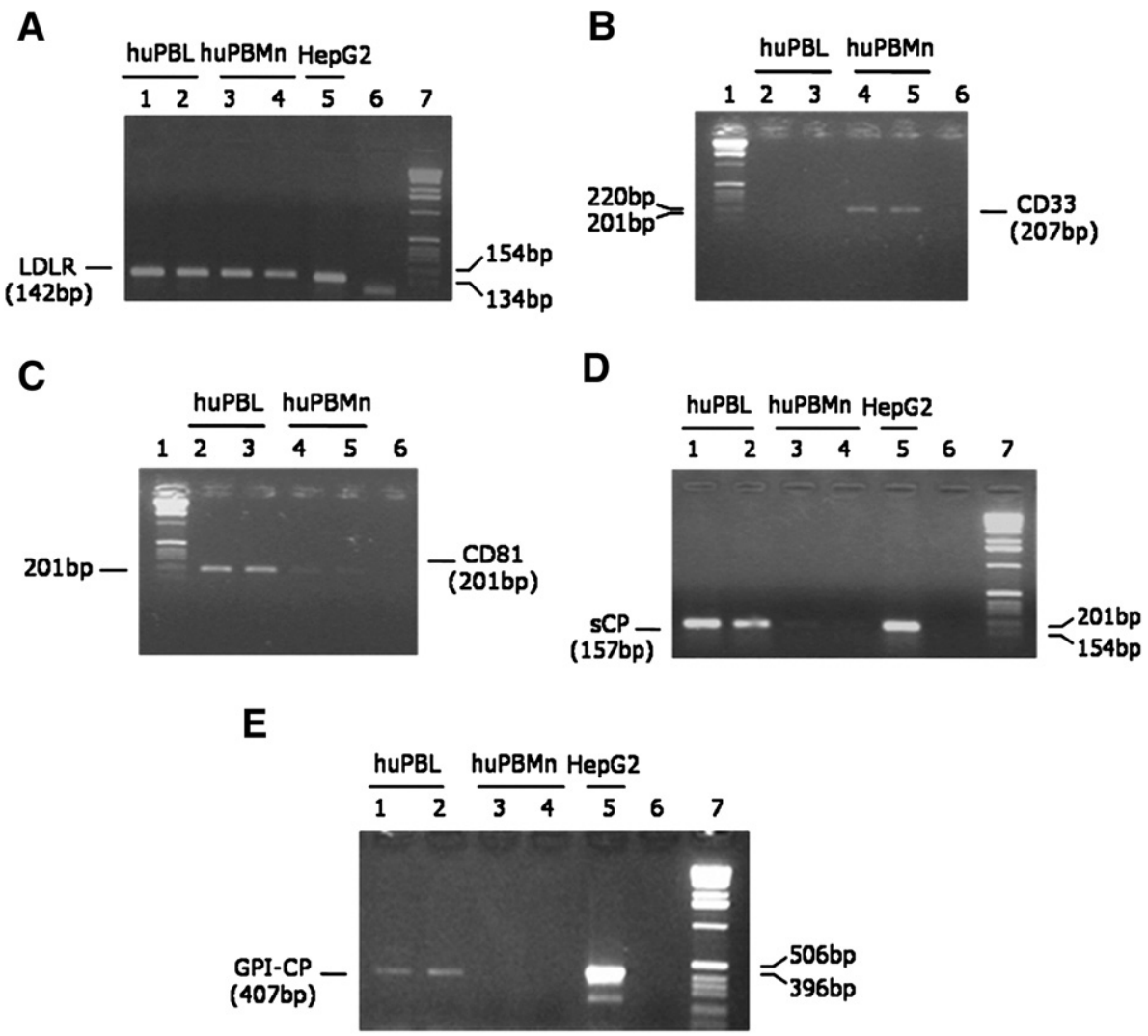

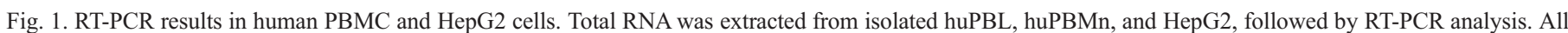

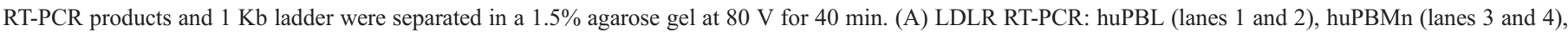

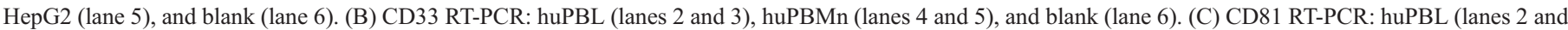

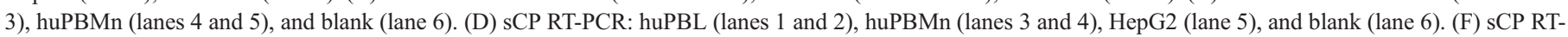
PCR: huPBL (lanes 1 and 2), huPBMn (lanes 3 and 4), HepG2 (lane 5), and blank (lane 6). In all cases, the amplification product was of the expected size. 
PBL transcriptional expression of secreted and membrane GPI-anchored ceruloplasmin

RT-PCR was used to evaluate the transcriptional expression of $\mathrm{CP}$ in huPBL. For this purpose, cDNA samples of huPBL were prepared and tested by PCR using primers specific for LDLR, CD81, CD33, sCP, and GPI-CP. Human peripheral blood monocyte (huPBMn) cDNA samples were also prepared as positive controls for CD33 PCR assay. HepG2 cDNA sample was used as a positive control for specific amplification of $\mathrm{sCP}$ [31] and GPI-CP [36].

The integrity of all cDNA samples was analyzed in a PCR assay for LDLR with successful amplification of all samples (Fig. 1A). HuPBL and huPBMn samples were tested by PCR for their specific markers (CD81 and CD33, respectively), confirming the successful isolation of both huPBL and huPBMn used for preparation of cDNA samples (Figs. 1B and C). HuPBL, huPBMn, and HepG2 samples were then tested for sCP and GPI-CP. As shown in Fig. 1, there was a successful amplification for both sCP (Fig. 1D) and GPI-CP (Fig. 1E) in huPBL and HepG2 samples. No amplification for GPI-CP transcript was detected in huPBMn samples while only a slight amplification was observed for sCP. This latter result is consistent with Mazumder et al's observation that $\mathrm{sCP}$ transcriptional expression is insignificant in resting monocytes [15], excluding a putative contribution of contaminating monocytes in huPBL samples.

The sequence of the amplified fragments was analyzed by DNA sequencing and compared to the nucleotide sequence for CP cDNA previously reported [31,37,38]. The

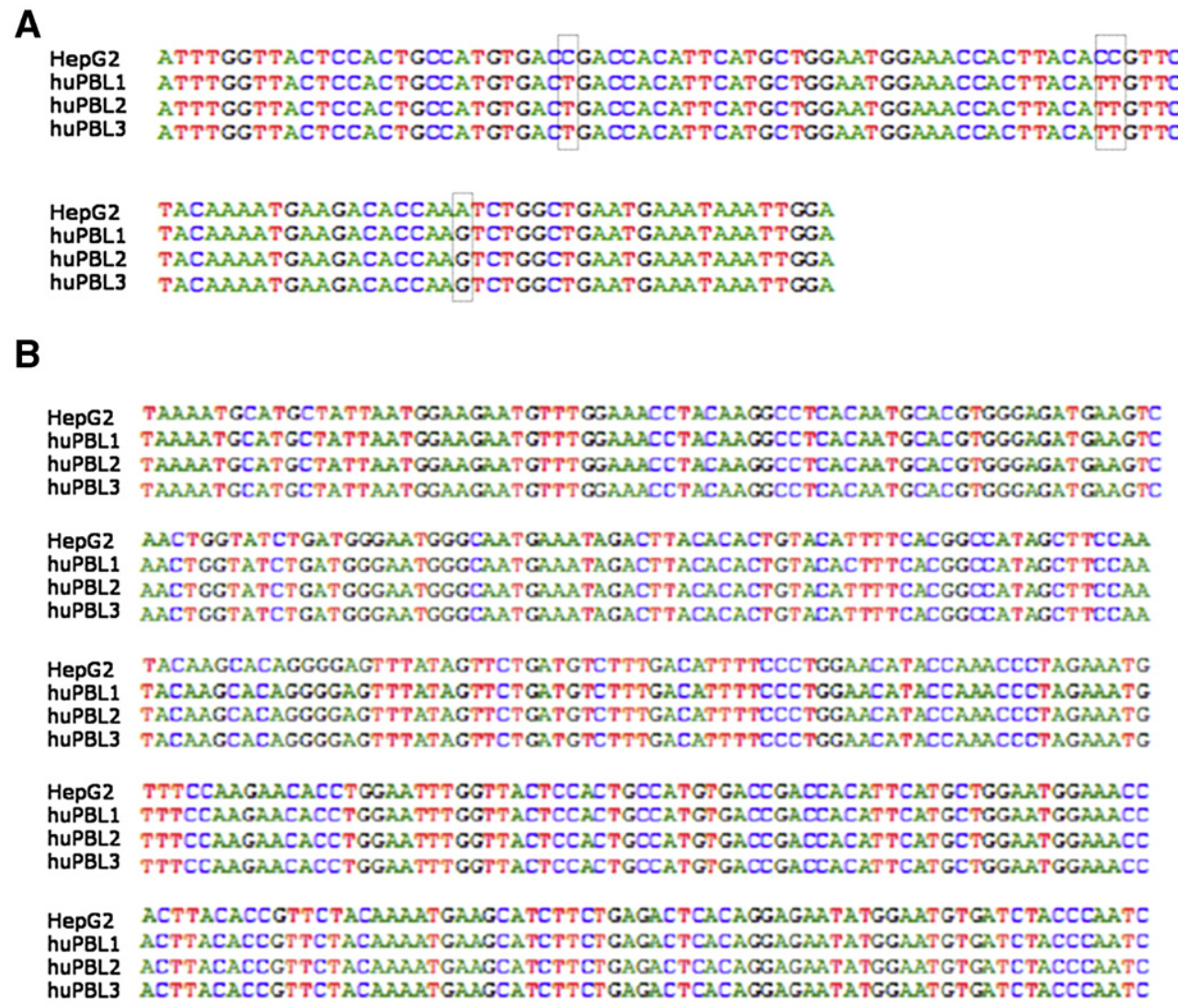

C

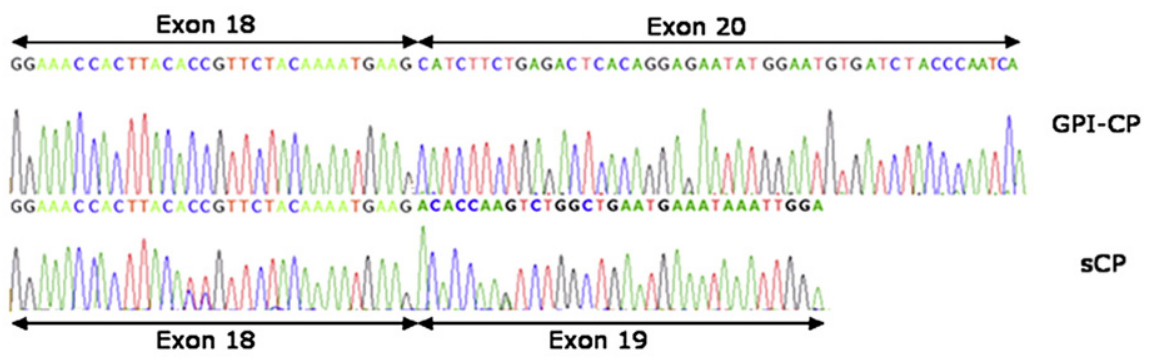

Fig. 2. Sequencing analysis of RT-PCR products for CP isoforms in huPBL and HepG2 cells. Total RNA was extracted from isolated huPBL and HepG2 followed by RT-PCR for GPI-CP and sCP. Amplified fragments were analyzed by DNA sequencing. (A) sCP sequence alignment for huPBL and HepG2 samples: polymorphic regions are shown in boxes. (B) GPI-CP alignment for huPBL and HepG2 samples. (C) Comparison between GPI-CP and sCP amplified sequences. 


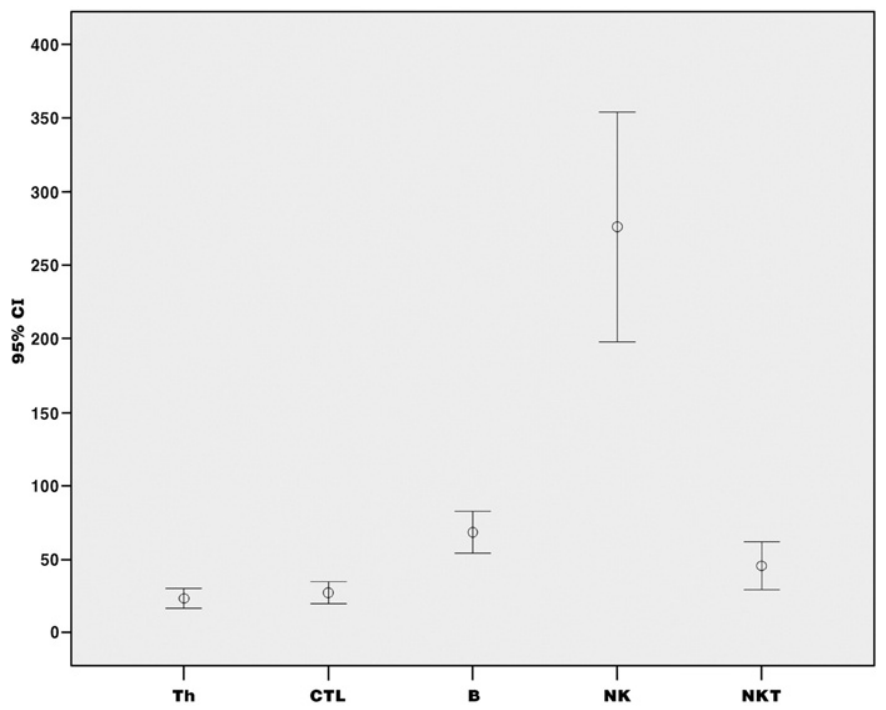

Fig. 3. Expression of CP in huPBL subsets: Th $(\mathrm{CD} 3+\mathrm{CD} 4+), n=17$; CTL $(\mathrm{CD} 3+$ CD8+), $n=17$; B lymphocytes (CD3-CD19+), $n=19$; NK cells (CD3-CD16+/ $\mathrm{CD} 56+), n=17$; NKT cells $(\mathrm{CD} 3+\mathrm{CD} 16+/ \mathrm{CD} 56+), n=18$. Mean and respective $95 \%$ confidence intervals.

identification of sCP and GPI-CP fragments was confirmed, showing that huPBL express the transcripts for sCP and GPICP (Figs. 2A and B). Also, it showed a different 3' terminal sequence for $\mathrm{CP}$ transcripts (Fig. 2C) with possible origin at an alternative splicing mechanism as reported elsewhere $[38,39]$.

Ceruloplasmin expression by huPBL subpopulations has a high pattern of cell-type specificity

Results obtained from flow cytometry analysis showed huPBL have differential $\mathrm{CP}$ expression according to the individual lymphocyte subset analyzed (Fig. 3). Importantly, despite that all the major lymphocyte subpopulations (Th, CTL, B, NK, and NKT lymphocytes) express CP, a highly celltype-specific expression was observed on a NK lymphocyte subset (CD3-CD16+/CD56+lymphocytes). Accordingly, a high correlation between CP expression in total huPBL and $\mathrm{CP}$ expressed in each lymphocyte subset was found, particularly with the NK cells subset (Pearson $r=0.962$ and Spearman $\left.r_{\mathrm{s}}=0.912, P<0.001\right)$. In fact, a good model fit was obtained for adjustment of NK cells expressing about $92 \%$ (adjusted $R^{2}$ ) of variation of CP in total huPBL (Fig. 4). The hypothesis of Normally distributed residuals was not rejected (Kolmogorov-Smirnov test), and autocorrelation was not present.

Additionally, individual comparisons between CP expression in differential huPBL subpopulations showed a significant difference between the NK cells expressing $\mathrm{CP}$ and all the others subsets analyzed (Fig. 3). CP expressed in B lymphocytes and NKT cells was statistically different between them in comparison with all the other subsets. However, no significant difference was observed in the expression of $\mathrm{CP}$ between Th cells and CTL.

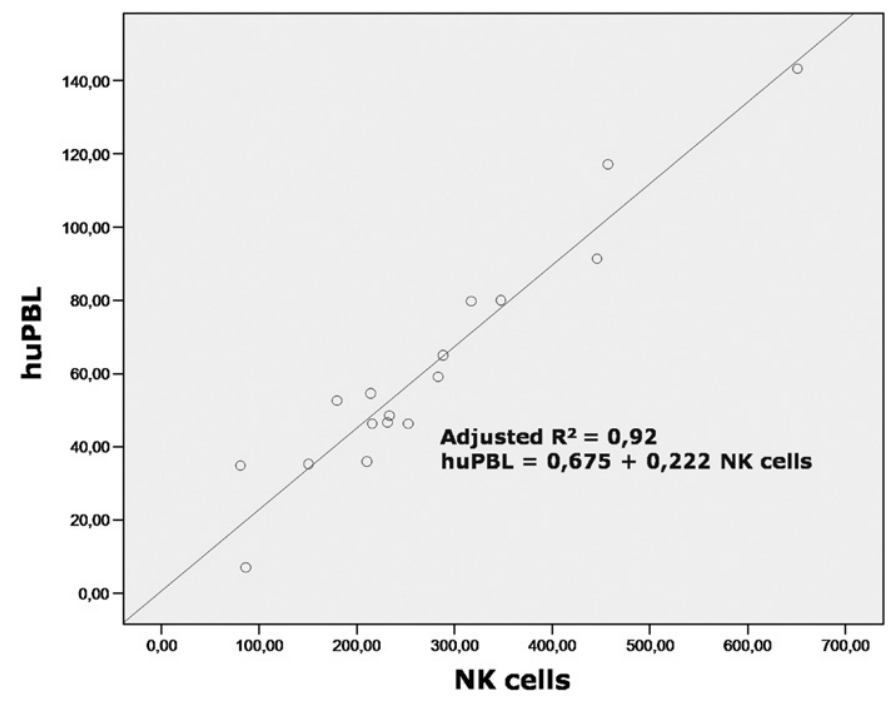

Fig. 4. Adjustment of NK cells to huPBL, using a linear regression model.

A search for putative correlations between hematological/ biochemical parameters and CP concentration in serum and/or $\mathrm{CP}$ expression in huPBL showed that $\mathrm{CP}$ expressed at the huPBL surface is not correlated with serum Fe or serum Tf but is inversely correlated (Pearson $r=-0.507, P=0.02$ ) with serum Ft. Remarkably, no association was found between serum CP and its expression on the huPBL surface in all population analyzed.

\section{Human PBL express ceruloplasmin protein at its surface}

Nonpermeabilized huPBL cells were labeled for $\mathrm{CP}$ and imaged using confocal microscopy (Fig. 5). Observation of the immunolabeling in the different sections of resting huPBL (Figs. $5 \mathrm{C}$ to $\mathrm{H}$ ) suggests that $\mathrm{CP}$ localizes essentially on the plasma membrane. In fact, the fluorescence intensity through the cell depicted in Fig. 6 is significantly higher on the cell periphery, giving further evidence for the presence of a $\mathrm{CP}$ membrane-bound isoform (Fig. 6).

\section{Discussion}

In this study, we have shown that huPBL express two distinct CP transcripts, namely the secreted and the membrane GPIanchored isoforms. Expression of CP in huPBL was confirmed at the protein level by flow cytometry analysis in all lymphocyte subpopulations studied. These observations are in agreement with previous detection of $\mathrm{CP}$ transcript in $\mathrm{CD} 4+$ cells, CD8+ cells and B lymphoblasts [32]. However, it is noteworthy to mention the significantly higher $\mathrm{CP}$ expression in NK cells compared to all other lymphocyte subsets analyzed. Moreover, flow cytometry and confocal microscopy analyses of immunolabeling on nonpermeabilized cells strongly indicate the presence of CP protein at the surface of huPBL. This cell surface staining of $\mathrm{CP}$ may indicate either expression of the membranebound GPI-CP form or binding of circulating CP. The statistical analysis showing no correlation between serum $\mathrm{CP}$ 

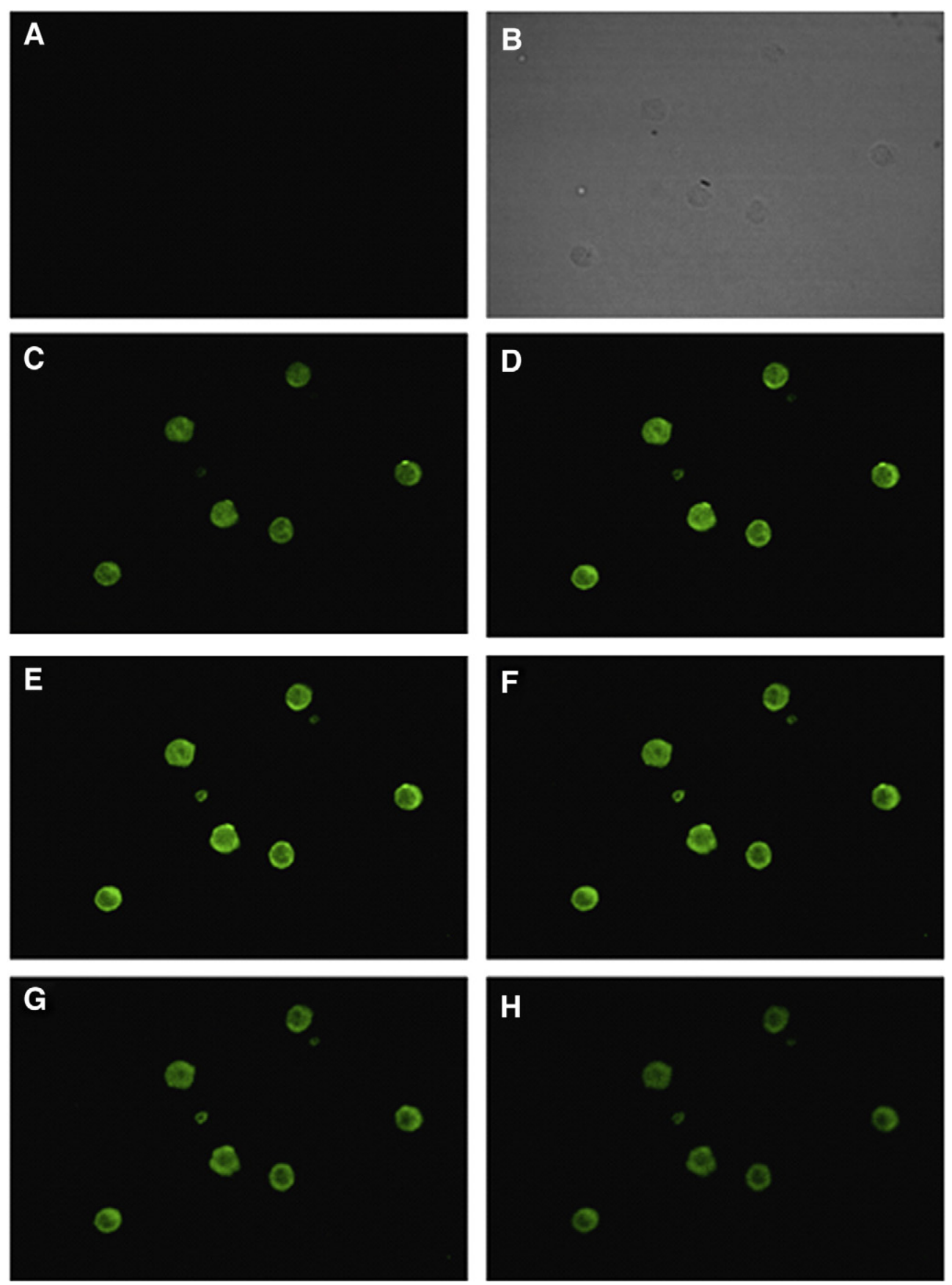

Fig. 5. Confocal imaging of CP immunolabelling in resting huPBL. Cells were fixed in $4 \%$ formaldehyde and stained with sheep anti-human CP-FITC conjugated (green): (A) unlabeled cells; (B-H) the same cells observed by phase contrast (B) or by fluorescence for CP in different confocal sections (B-H).

concentration and $\mathrm{CP}$ cell surface staining in these cells exclude, at least in part, the hypothesis of exogenous circulating $\mathrm{CP}$ binding and reinforce the hypothesis of GPI-CP protein expression in huPBL.

The role of CP ferroxidase activity on cellular Fe efflux and defense against oxidative stress has received considerable attention over the last years. Since its discovery, the source of circulating $\mathrm{CP}$ has been almost exclusively assigned to $\mathrm{CP}$ secreted by hepatocytes. However, CP transcripts produced by alternative splicing [40] were previously detected in different tissues. Human monocytic cells have also been shown to pro- duce and secrete their own $\mathrm{CP}$ on activation [15]. Here, we have shown that huPBL express the transcripts for both CP molecular isoforms. During infection and inflammation characterized by active proliferation of circulating lymphocytes, $\mathrm{CP}$ concentration in serum increases, suggesting that the expression of the CP gene represents an essential part of host response to immunological stress [40]. Therefore, it will be of interest to study the relative contribution of PBL-derived $\mathrm{CP}$ to the increase of serum $\mathrm{CP}$ observed in specific physiological and pathological conditions. Since both sCP and GPI-CP transcripts were detected, one can speculate for either the direct secretion and/or cell 


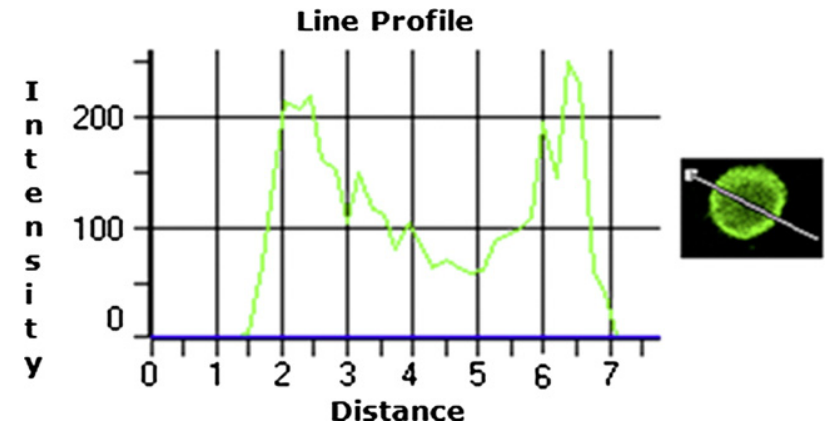

Fig. 6. Histogram reflecting the fluorescence intensity of $\mathrm{CP}$ through a line intersecting one section of a huPBL.

surface shedding of CP. It has been described that GPI proteins expressed at the cell surface of NK cells can be converted during activation to a soluble form in extracellular medium through a proteolytic cleavage involving a metalloprotease [41].

There is now compelling evidence that lymphocytes are involved in the regulation of Fe metabolism, namely through the synthesis or specific binding of several "Fe-related proteins" [42-45]. In this context, lymphocyte CP expression gives additional support to the original postulate from De Sousa et al. addressing a role for lymphocyte circulation in the regulation of Fe load [19] and establishes an additional link between immune system and $\mathrm{Fe}$ homeostasis.

In fact, lymphocytes have the capability to circulate, populate, and interact with cells and tissues. Interestingly, lymphocytes were also shown to synthesize the $\mathrm{Fe}(\mathrm{III})$ acceptor $\mathrm{Tf}$ [44]. A coordinated secretion of $\mathrm{CP}$ and $\mathrm{Tf}$ by huPBL may represent a protective function against the potential toxicity of $\mathrm{Fe}$ and its deposition in tissues. Indeed, CP may play an important role in the radical driven process and oxidative injury characteristic of Fe overload diseases such as HH [46]. Consistent with the role of $\mathrm{CP}$ as an endogenous antioxidant and scavenger of superoxide anion radicals, low numbers of local and/or circulating CP producing cells could predict a more severe presentation in $\mathrm{HH}$ patients and could also constitute an additional factor explaining clinical heterogeneity of the pathology. Several reports show that serum CP $[47,48]$ and its ferroxidase activity [49] are decreased in $\mathrm{HH}$ patients. Moreover, defective numbers of huPBL were associated with a greater degree of Fe loading in $\mathrm{HH}$ [50] while $\mathrm{Fe}$ deposition and damage in liver from $\mathrm{HH}$ patients were shown to be associated with low numbers of CD8+ cells in the lobuli [51]. Interestingly, in healthy individuals liverassociated lymphocytes are characterized by a three-fold increase in the percentage of CD56+ cells (NK cells) and also an increase in the percentage of $\mathrm{CD} 8+$ cells compared to PBL [52]. Previous studies showed that the lowest numbers of NK cells were found in a group of $\mathrm{HH}$ patients with cirrhosis compared to asymptomatic patients [53] while a diminished NK activity in Fe overload conditions $[54,55]$ has also been reported. Altogether, these observations underline a close link between Fe homeostasis and impairment of NK function. We have observed that NK cells are the subset of lymphocytes presenting the highest expression of CP. In this context, it is therefore tempting to speculate that a decrease in lymphocyte population, especially in NK cells, could be involved in the pathophysiology of $\mathrm{Fe}$ overload, namely in hepatic tissues through a possible impairment of lymphocyte CP ferroxidase activity restricting proper $\mathrm{Fe}$ egress from cells.

An additional putative functional relationship between immune function and $\mathrm{Fe}$ metabolism through huPBL-derived $\mathrm{CP}$ could be related to the widely reported role of NK cells in infection and tumorigenesis. Previous studies have shown cellular Fe depletion as an effective host defense mechanism against pathogenic microorganisms and neoplasia [56], indicating a possible involvement for NK cell-derived $\mathrm{CP}$ in these processes. Increased levels of serum $\mathrm{CP}$ have been reported to occur in both human [57,58] and transgenic mice [59] hepatocellular carcinoma. The induction of $\mathrm{CP}$ production may represent a possible compensatory mechanism to control excessive cell proliferation by decreasing liver $\mathrm{Fe}$ due to its role on $\mathrm{Fe}$ egress from cells. Furthermore, through its protective function against oxidative stress, CP may also inhibit potential DNA damage and mutations which could potentiate tumor severity. The antitumor activity of $\mathrm{CP}[60]$ could be of special interest in $\mathrm{HH}$ considering the high incidence of cancer in these patients [61].

Alternatively, huPBL-derived $\mathrm{CP}$ physiological function may be directly related to its prooxidant activity. NK lymphocytes are known to have a key role on cell-mediated cytotoxicity. The potential mechanisms for cytotoxic damage to targets cells involve NK cells' release of breakdown enzymes or other toxic substances able to cause profound cell damage. In this context, secretion or shedding of NK cell-derived CP may also contribute to cell-mediated host defense processes acting through its prooxidant properties in a manner analogous to the release of oxygen and nitrogen species. Indeed, CP was shown to present some bactericidal activity [62] and to suppress respiratory burst in phagocytic cells under $\mathrm{Cu}$ deficiency conditions [13]. On the other hand, the surface expression of the GPI-CP isoform on effector cells could function as a cytoprotective barrier in a harmful environment, namely through its antioxidant capacity.

In conclusion, several lines of evidence suggest a close functional relationship among the immune system, oxidative stress, and Fe metabolism through huPBL-derived CP. However, the precise role of $\mathrm{CP}$ expressed by lymphocytes on $\mathrm{Fe}$ metabolism and host defense mechanisms needs to be investigated. In particular, the physiological function assigned to the two specific CP isoforms (sCP or GPI-CP) expressed by huPBL needs to be clarified.

\section{Acknowledgments}

This study was supported by Instituto Nacional de Saúde Dr. Ricardo Jorge (BIC/07/2004-IV and BID 02/2006-I). We acknowledge all the members of Núcleo de Diagnóstico do Centro de Biopatologia from Instituto Nacional de Saúde Dr. Ricardo Jorge for the collaboration on the hematological and biochemical characterization of samples. 


\section{Appendix A. Supplementary data}

Supplementary data associated with this article can be found, in the online version, at doi:10.1016/j.freeradbiomed.2007.10.032.

\section{References}

[1] Frieden, E. Ceruloplasmin, a link between copper and iron metabolism. Ortop. Travmatol. Protez. 30:87-91; 1969.

[2] Harris, E. D. Copper transport: an overview. Proc. Soc. Exp. Biol. Med. 196:130-140; 1991.

[3] Osaki, S.; Johnson, D. A. Mobilization of liver iron by ferroxidase (ceruloplasmin). J. Biol. Chem. 244:5757-5758; 1969.

[4] Osaki, S.; Johnson, D. A.; Frieden, E. The possible significance of the ferrous oxidase activity of ceruloplasmin in normal human serum. J. Biol. Chem. 241:2746-2751; 1966

[5] Van Eden, M. E.; Aust, S. D. Intact human ceruloplasmin is required for the incorporation of iron into human ferritin. Arch. Biochem. Biophys. 381:119-126; 2000.

[6] Goldstein, I. M.; Kaplan, H. B.; Edelson, H. S.; Weissmann, G. Ceruloplasmin: ascavenger of superoxide anion radicals. J. Biol. Chem. 254:4040-4045; 1979.

[7] Graf, W. D.; Noetzel, M. J. Radical reactions from missing ceruloplasmin: the importance of a ferroxidase as an endogenous antioxidant. Neurology 53:446-447; 1999.

[8] Fox, P. L.; Mukhopadhyay, C.; Ehrenwald, E. Structure, oxidant activity, and cardiovascular mechanisms of human ceruloplasmin. Life Sci. 56:1749-1758; 1995.

[9] Gitlin, J. D. Transcriptional regulation of ceruloplasmin gene expression during inflammation. J. Biol. Chem. 263:6281-6287; 1988.

[10] Moak, S. A.; Greenwald, R. A. Enhancement of rat serum ceruloplasmin levels by exposure to hyperoxia. Proc. Soc. Exp. Biol. Med. 177:97-103; 1984.

[11] Cousins, R. J. Absorption, transport, and hepatic metabolism of copper and zinc: special reference to metallothionein and ceruloplasmin. Physiol. Rev. 65:238-309; 1985.

[12] Babu, U.; Failla, M. L. Copper status and function of neutrophils are reversibly depressed in marginally and severely copper-deficient rats. J. Nutr. 120:1700-1709; 1990.

[13] Babu, U.; Failla, M. L. Respiratory burst and candidacidal activity of peritoneal macrophages are impaired in copper-deficient rats. J. Nutr. 120:1692-1699; 1990.

[14] Bala, S.; Failla, M. L.; Lunney, J. K. Alterations in splenic lymphoid cell subsets and activation antigens in copper-deficient rats. J. Nutr. 121:745-753; 1991.

[15] Mazumder, B.; Mukhopadhyay, C. K.; Prok, A.; Cathcart, M. K.; Fox, P. L. Induction of ceruloplasmin synthesis by IFN-gamma in human monocytic cells. J. Immunol. 159:1938-1944; 1997.

[16] Ramadori, G.; Van Damme, J.; Rieder, H.; Meyer zum Buschenfelde, K. $\mathrm{H}$. Interleukin 6, the third mediator of acute-phase reaction, modulates hepatic protein synthesis in human and mouse. Comparison with interleukin 1 beta and tumor necrosis factor-alpha. Eur. J. Immunol. 18:1259-1264; 1988.

[17] Fleming, R. E.; Whitman, I. P.; Gitlin, J. D. Induction of ceruloplasmin gene expression in rat lung during inflammation and hyperoxia. Am. $J$. Physiol. 260:L68-L74; 1991.

[18] Weiss, G.; Wachter, H.; Fuchs, D. Linkage of cell-mediated immunity to iron metabolism. Immunol. Today 16:495-500; 1995.

[19] De Sousa, M. Lymphoid cell positioning: a new proposal for the mechanism of control of lymphoid cell migration. Symp. Soc. Exp. Biol. 32:393-410; 1978.

[20] de Sousa, M. Immune cell functions in iron overload. Clin. Exp. Immunol. 75:1-6; 1989.

[21] de Sousa, M.; Porto, G.; Arosa, F.; Cardoso, C.; Cabeda, J.; Lacerda, R.; Fraga, J. T lymphocyte expression and function in hemochromatosis. Hemochromatosis. genetics, pathophysiol., diagnosis and treatment Cambridge University Press, Cambridge, pp. 396-407; 2000.
[22] Gerhard, G. S.; Ten Elshof, A. E.; Chorney, M. J. Hereditary haemochromatosis as an immunological disease. Br. J. Haematol. 100:247-255; 1998.

[23] Santos, M.; Schilham, M. W.; Rademakers, L. H.; Marx, J. J.; de Sousa, M.; Clevers, H. Defective iron homeostasis in beta 2-microglobulin knockout mice recapitulates hereditary hemochromatosis in man. J. Exp. Med. 184:1975-1985; 1996.

[24] Feder, J. N.; Tsuchihashi, Z.; Irrinki, A.; Lee, V. K.; Mapa, F. A.; Morikang, E.; Prass, C. E.; Starnes, S. M.; Wolff, R. K.; Parkkila, S.; Sly, W. S.; Schatzman, R. C. The hemochromatosis founder mutation in HLA-H disrupts beta2-microglobulin interaction and cell surface expression. J. Biol. Chem. 272:14025-14028; 1997.

[25] Aldred, A. R.; Grimes, A.; Schreiber, G.; Mercer, J. F. Rat ceruloplasmin. Molecular cloning and gene expression in liver, choroid plexus, yolk sac, placenta, and testis. J. Biol. Chem. 262:2875-2878; 1987.

[26] Jaeger, J. L.; Shimizu, N.; Gitlin, J. D. Tissue-specific ceruloplasmin gene expression in the mammary gland. Biochem. J. 280 (Pt 3):671-677; 1991.

[27] Klomp, L. W.; Gitlin, J. D. Expression of the ceruloplasmin gene in the human retina and brain: implications for a pathogenic model in aceruloplasminemia. Hum. Mol. Genet. 5:1989-1996; 1996.

[28] Patel, B. N.; David, S. A novel glycosylphosphatidylinositol-anchored form of ceruloplasmin is expressed by mammalian astrocytes. J. Biol. Chem. 272:20185-20190; 1997.

[29] Mittal, B.; Doroudchi, M. M.; Jeong, S. Y.; Patel, B. N.; David, S. Expression of a membrane-bound form of the ferroxidase ceruloplasmin by leptomeningeal cells. Glia 41:337-346; 2003.

[30] Fortna, R. R.; Watson, H. A.; Nyquist, S. E. Glycosyl phosphatidylinositolanchored ceruloplasmin is expressed by rat Sertoli cells and is concentrated in detergent-insoluble membrane fractions. Biol. Reprod. 61:1042-1049; 1999.

[31] Yang, F.; Naylor, S. L.; Lum, J. B.; Cutshaw, S.; McCombs, J. L.; Naberhaus, K. H.; McGill, J. R.; Adrian, G. S.; Moore, C. M.; Barnett, D. R., et al. Characterization, mapping, and expression of the human ceruloplasmin gene. Proc. Natl. Acad. Sci. U. S. A. 83:3257-3261; 1986.

[32] Pan, Y.; Katula, K.; Failla, M. L. Expression of ceruloplasmin gene in human and rat lymphocytes. Biochim. Biophys. Acta 1307:233-238; 1996.

[33] Bourbon, M. Characterization of molecular defects in Portuguese patients with familial hypercholesterolaemia. University of London, Faculty of Med., Imperial College. London; 2006.

[34] Hall, T. A. BioEdit: a user-friendly biological sequence alignment editor and analysis program for Windows 95/98/NT. Nucleic Acids Symp. Ser. 41:95-98; 1999.

[35] Camacho, L.; Parton, R. M.; Trewavas, A. J.; Malhó, R. [Ca2+]c distribution and oscillations in pollen tubes with confocal microscopy. A comparison of different dyes and loading methods. Protoplasma 212:162-173; 2000.

[36] Platonova, N. A.; Vasin, A. V.; Klotchenko, S. A.; Tsymbalenko, N. V.; Puchkova, L. V. The revelation of expressing region in the processed ceruloplasmin gene in human genome by biocomputational and biochemical methods. Biophys. Chem. 115:247-250; 2005.

[37] Daimon, M.; Yamatani, K.; Igarashi, M.; Fukase, N.; Kawanami, T.; Kato, T.; Tominaga, M.; Sasaki, H. Fine structure of the human ceruloplasmin gene. Biochem. Biophys. Res. Commun. 208:1028-1035; 1995.

[38] Hellman, N. E.; Kono, S.; Miyajima, H.; Gitlin, J. D. Biochemical analysis of a missense mutation in aceruloplasminemia. J. Biol. Chem. 277:1375-1380; 2002.

[39] Patel, B. N.; Dunn, R. J.; David, S. Alternative RNA splicing generates a glycosylphosphatidylinositol-anchored form of ceruloplasmin in mammalian brain. J. Biol. Chem. 275:4305-4310; 2000.

[40] Hellman, N. E.; Gitlin, J. D. Ceruloplasmin metabolism and function. Anпu. Rev. Nutr. 22:439-458; 2002.

[41] Giustiniani, J.; Marie-Cardine, A.; Bensussan, A. A soluble form of the MHC class I-specific CD160 receptor is released from human activated NK lymphocytes and inhibits cell-mediated cytotoxicity. J. Immunol. 178:1293-1300; 2007.

[42] Dorner, M. H.; Silverstone, A.; Nishiya, K.; de Sostoa, A.; Munn, G.; de Sousa, M. Ferritin synthesis by human T lymphocytes. Science 209:1019-1021; 1980.

[43] Phillips, J. L. Specific binding of zinc transferrin to human lymphocytes. Biochem. Biophys. Res. Commun. 72:634-639; 1976. 
[44] Soltys, H. D.; Brody, J. I. Synthesis of transferrin by human peripheral blood lymphocytes. J. Lab. Clin. Med. 75:250-257; 1970.

[45] Van Snick, J. L.; Masson, P. L. The binding of human lactoferrin to mouse peritoneal cells. J. Exp. Med. 144:1568-1580; 1976.

[46] Stremmel, W.; Riedel, H. D.; Niederau, C.; Strohmeyer, G. Pathogenesis of genetic haemochromatosis. Eur. J. Clin. Investig. 23:321-329; 1993.

[47] Cairo, G.; Conte, D.; Bianchi, L.; Fraquelli, M.; Recalcati, S. Reduced serum ceruloplasmin levels in hereditary haemochromatosis. Br. J. Haematol. 114:226-229; 2001.

[48] Del Rey, R.; Froilan, C.; Comas, C.; Villanueva, R.; Olveira, A. Hereditary hemochromatosis associated with hypoceruloplasminemia with absence of mutations in the HFE gene. Rev. Esp. Enferm. Dig. 92:610-611; 2000.

[49] Laine, F.; Ropert, M.; Lan, C. L.; Loreal, O.; Bellissant, E.; Jard, C.; Pouchard, M.; Le Treut, A.; Brissot, P. Serum ceruloplasmin and ferroxidase activity are decreased in HFE C282Y homozygote male ironoverloaded patients. J. Hepatol. 36:60-65; 2002.

[50] Porto, G.; Cardoso, C. S.; Gordeuk, V.; Cruz, E.; Fraga, J.; Areias, J.; Oliveira, J. C.; Bravo, F.; Gangaidzo, I. T.; MacPhail, A. P.; Gomo, Z. A.; Moyo, V. M.; Melo, G.; Silva, C.; Justica, B.; de Sousa, M. Clinical and genetic heterogeneity in hereditary haemochromatosis: association between lymphocyte counts and expression of iron overload. Eur. J. Haematol. 67:110-118; 2001.

[51] Cardoso, E. M.; Hagen, K.; de Sousa, M.; Hultcrantz, R. Hepatic damage in $\mathrm{C} 282$ Y homozygotes relates to low numbers of CD8+ cells in the liver lobuli. Eur. J. Clin. Investig. 31:45-53; 2001.

[52] Winnock, M.; Garcia Barcina, M.; Lukomska, B.; Huet, S.; Saric, J.; Balabaud, C.; Bioulac-Sage, P. Human liver-associated lymphocytes: an overview. J. Gastroenterol. Hepatol. 10 (Suppl. 1):S43-S46; 1995.
[53] Cruz, E.; Lacerda, R.; Porto, G. NK cell number in hereditary hemochromatosis. XXVI Annual Meeting of the Portuguese Society of Immunol. Porto; 2000

[54] Akbar, A. N.; Fitzgerald-Bocarsly, P. A.; de Sousa, M.; Giardina, P. J.; Hilgartner, M. W.; Grady, R. W. Decreased natural killer activity in thalassemia major: a possible consequence of iron overload. J. Iттипоl. 136: $1635-1640 ; 1986$.

[55] Akbar, A. N.; Fitzgerald-Bocarsly, P. A.; Giardina, P. J.; Hilgartner, M. W.; Grady, R. W. Modulation of the defective natural killer activity seen in thalassaemia major with desferrioxamine and alpha-interferon. Clin. Exp. Immunol. 70:345-353; 1987.

[56] Weinberg, E. D. Iron depletion: a defense against intracellular infection and neoplasia. Life Sci. 50:1289-1297; 1992.

[57] Senra Varela, A.; Lopez Saez, J. J.; Quintela Senra, D. Serum ceruloplasmin as a diagnostic marker of cancer. Cancer Lett. 121:139-145; 1997.

[58] Knekt, P.; Aromaa, A.; Maatela, J.; Rissanen, A.; Hakama, M.; Aaran, R. K.; Nikkari, T.; Hakulinen, T.; Peto, R.; Teppo, L. Serum ceruloplasmin and the risk of cancer in Finland. Br. J. Cancer 65:292-296; 1992.

[59] Pousset, D.; Piller, V.; Bureaud, N.; Piller, F. High levels of ceruloplasmin in the serum of transgenic mice developing hepatocellular carcinoma. Eur. J. Biochem. / FEBS 268:1491-1499; 2001.

[60] Itoh, O.; Torikai, T.; Satoh, M.; Okumura, O.; Osawa, T. Antitumor and toxohormone-neutralizing activities of human ceruloplasmin. Gann Gan 72:370-376; 1981.

[61] Bomford, A.; Williams, R. Long term results of venesection therapy in idiopathic haemochromatosis. Q. J. Med. 45:611-623; 1976.

[62] Klebanoff, S. J. Bactericidal effect of $\mathrm{Fe} 2+$, ceruloplasmin, and phosphate. Arch. Biochem. Biophys. 295:302-308; 1992. 